\title{
Emergency contraception and prevention of induced abortion in India
}

\author{
Nalini Arora, Suneeta Mittal
}

\begin{abstract}
Objective Induced abortion is associated with high morbidity and mortality in India. Use of regular contraception with emergency contraception (EC) as backup can reduce the incidence of induced abortion. The study aimed to assess women's knowledge, practice, preference and acceptance of different contraceptive methods with special reference to the causes of induced abortion, and their willingness to use hormonal EC.

Methods The study comprised a structured questionnaire survey conducted in the family planning clinic of a tertiary teaching hospital in New Delhi, India. A total of 623 women and three men seeking contraceptive advice and/or termination of pregnancy were interviewed. The main outcome measures were knowledge of different contraceptive methods including $\mathrm{EC}$ and the reasons for unintended pregnancy.
\end{abstract}

Results More than $99 \%$ of the respondents knew about most of the modern methods of contraception whereas only 37 (5.9\%; 95\% Cl 4.0-7.8) of the respondents knew about EC and none of them had ever used it. Contraceptive method failure led to unintended pregnancy in $39.1 \%(95 \% \mathrm{Cl} 33.7-44.5)$ of abortion seekers. Correct use of EC could have prevented nearly $65.5 \%(95 \% \mathrm{Cl}$ 57.0-74.0) of induced abortions due to contraceptive method failure and $25.6 \%(95 \% \mathrm{Cl} 20.7-30.5)$ of all induced abortions.

Conclusions More efforts are required to generate awareness about the safety, efficacy and availability of $\mathrm{EC}$, regular use of effective contraception and the health hazards of induced abortion.

J Fam Plann Reprod Health Care 2005; 31(4): 294-296 (Accepted 25 April 2005)

\section{Key message points \\ - Lack of awareness about emergency contraception (EC) among Indian women is a major concern. \\ - Contraceptive method failure led to unintended pregnancy in $39 \%$ of abortion seekers. Correct use of EC could have prevented nearly two-thirds of induced abortions due to contraceptive method failure and a quarter of all induced abortions. \\ - There is a need to organise a co-ordinated, multifaceted information campaign for the general public regarding the safety, efficacy and availability of EC, use of effective contraception, and health hazards of induced abortion.}

Department of Obstetrics and Gynaecology, Lady Hardinge Medical College, New Delhi, India Nalini Arora, MD, DNB, Assistant Professor

Department of Obstetrics and Gynaecology, All India Institute of Medical Sciences, New Delhi, India

Suneeta Mittal, MD, FAMS, Professor and Head

Correspondence to: Dr Nalini Arora, Department of Obstetrics and Gynaecology, Lady Hardinge Medical College, New Delhi 110001, India. Tel: +91 112336 3758/3968.

E-mail: njana1@vsnl.net

\section{Introduction}

Contraceptive behaviour and acceptance in India has changed markedly over the past few decades. In spite of this, the number of unplanned and unintended pregnancies remains high. According to the National Family Health Survey (NFHS-2), ${ }^{1} 21 \%$ of all pregnancies that resulted in live births in the 3 -year period (1996-1998) preceding the survey were unplanned. Of these, $12 \%$ pregnancies were wanted later and $9 \%$ were not wanted at all. ${ }^{1}$ In the same survey it was estimated that $2 \%$ of all pregnancies of ever-married women aged 15-49 years resulted in induced abortions. More than 50 000 induced abortions have been reported annually from institutions approved for medical termination of pregnancy. ${ }^{2}$ However, this number reflects only the tip of the iceberg, as it is also estimated that in India alone every year a further 5-6 million induced abortions are conducted by private practioners. ${ }^{3,4}$ The majority of these abortions are illegally carried out by untrained village practitioners, resulting in high abortion-related morbidity and mortality. 3,4

Hormonal emergency contraception (EC) (Yuzpe or levonorgestrel-only regimen) prevents about $75 \%$ of unintended pregnancies after unprotected intercourse or accidental contraceptive method failure. ${ }^{5-8}$ It is easy and safe to use, and has minimal side effects. 8,9 Thus, EC as a backup method has great potential to reduce a substantial number of induced abortions in India. For EC to become a widely used backup method of contraception, women require both an awareness of its existence and a willingness to use it correctly. ${ }^{10}$

Contraceptive practices in India vary widely depending on the knowledge, attitude and demographic characteristics of the women concerned.1,11 The present survey was carried out to assess women's knowledge, practice, preference and acceptance of different contraceptive methods with special reference to the causes of induced abortion, and their willingness to use hormonal EC. It was envisaged that the survey results would give an indication of the proportion of induced abortions that could have been prevented by prior knowledge and availability of EC.

Such a survey would also assist policymakers in targeting educational efforts regarding knowledge, use and availability of EC, which in future may reduce the number of induced abortions in India.

\section{Methods}

In a prospective survey conducted from July 2001 to June 2002 , we interviewed 626 participants (623 women and three men) who attended the family planning clinic (FPC) at the All India Institute of Medical Sciences in New Delhi seeking contraceptive advice and/or termination of pregnancy. The participants were residents of Delhi or the adjoining states. As the respondents belonged to all socioeconomic strata, the study population was representative of the wider population (Table 1). The participants were approached for an interview at random while they were waiting in the FPC for a consultation. None of those approached refused to participate, and so the response rate was $100 \%$.

A structured questionnaire was completed by a medical 
Table 1 Demographic characteristics of the respondents $(\mathrm{n}=626)$

\begin{tabular}{|c|c|c|}
\hline Characteristic & $n$ & $\%$ \\
\hline \multicolumn{3}{|l|}{ Sex } \\
\hline Female & 623 & 99.5 \\
\hline Male & 3 & 0.5 \\
\hline \multicolumn{3}{|l|}{ Religion } \\
\hline Hindu & 568 & 90.7 \\
\hline Muslim & 22 & 3.5 \\
\hline Christian & 24 & 3.8 \\
\hline Sikh & 12 & 1.9 \\
\hline \multicolumn{3}{|l|}{ Age (years) } \\
\hline $16-25$ & 163 & 26.0 \\
\hline $26-35$ & 410 & 65.5 \\
\hline $36-45$ & 53 & 8.5 \\
\hline \multicolumn{3}{|l|}{ Education } \\
\hline None & 65 & 10.4 \\
\hline Primary & 114 & 18.2 \\
\hline Intermediate & 257 & 41.1 \\
\hline Graduate & 106 & 16.9 \\
\hline Postgraduate/professional & 84 & 13.4 \\
\hline \multicolumn{3}{|l|}{ Age at marriage (years) } \\
\hline$<20$ & 277 & 44.3 \\
\hline $20-29$ & 345 & 55.1 \\
\hline$\geq 30$ & 4 & 0.6 \\
\hline \multicolumn{3}{|l|}{ Employment } \\
\hline Employed & 180 & 28.8 \\
\hline Unemployed & 446 & 71.2 \\
\hline \multicolumn{3}{|c|}{ Monthly family income (rupees) } \\
\hline$\geq 5000$ & 282 & 45.0 \\
\hline $5001-10000$ & 167 & 26.7 \\
\hline $10001-15000$ & 106 & 16.9 \\
\hline$\geq 15000$ & 71 & 11.3 \\
\hline
\end{tabular}

doctor and included questions on the following topics: age at marriage, education, occupation, religion, number of living children and the number of spontaneous and/or induced abortions. For the abortion seekers, causes of unwanted pregnancy were explored, namely whether the pregnancy was due to failure to use any contraception or failure of the contraceptive method used. If it was due to contraceptive method failure, further questions were asked regarding the kind of contraceptive method used at that time. The respondents were also asked about their awareness of different contraceptive methods including EC, and previous and current use of different methods with duration of use.

The acceptability of EC was assessed by asking the respondents whether they would have tried to avoid an unwanted pregnancy or abortion if they had known about $\mathrm{EC}$, and whether these women would wish to use such a method in the future in the event of recognisable contraception failure or unprotected sex.

Information was also collected regarding the respondents' preferences for the gender of their child(ren), family size, ideal birth intervals, resumption of sexual activity and use of any contraceptive method in the immediate postpartum period. To estimate the proportion of induced abortions that could have been avoided through the use of EC, the denominator includes those women who requested an abortion at the current visit to the FPC.

\section{Results}

\section{Demography}

The age range of the cohort at the time of the survey was 18-43 years with a mean of 28.6 years (SD 4.6). All the respondents were married and the majority $(73 \%)$ were multiparous. The mean age at marriage was 20.3 years (SD 3.5 ) with a wide age range of 9 to 34 years. The literacy rate was $89 \%$ and nearly one-third $(28.8 \%)$ of the respondents were employed (Table 1 ). The total monthly family income was less than 10000 Indian rupees (US\$ 220$)$ for the majority $(71.7 \%)$ of respondents.

\section{Contraception and family planning perception}

Although knowledge about modern methods of contraception was almost universal (99\%), only 37 (5.9\%; 95\% CI 4.0-7.8) of the respondents knew about EC and none of them had ever used it (Table 2). However, almost all of the respondents $(99.7 \%)$ thought that it would be a useful backup method and safer than induced abortion, and they were keen to use it if the need arose in the future.

Most of the respondents (96\%) had used contraception. Condoms were the commonest $(56.5 \%)$ temporary method ever used followed by intrauterine devices (IUDs) (52.4\%). Of the 626 participants, $192(30.7 \%)$ had requested sterilisation (189 tubal sterilisation, three vasectomy), which was carried out soon after the interview (Table 2).

All the respondents agreed that family planning is essential. Although the majority $(80.8 \%)$ wanted a family size of two children, 1 in 10 respondents wanted one child only, and the remainder wanted three or more children. Gender preference in favour of a son was more common $(57.8 \%)$ than no preference $(42.2 \%)$. The majority $(85.8 \%)$ wanted spacing between successive childbirths of at least 3 years or more.

\section{$E C$ and induced abortions}

About half $(322 / 623,51.7 \%)$ the women underwent induced abortions at the current visit to the FPC; 75 (20.3\%) of these women reported having had more than one abortion. The reasons for the current unwanted pregnancies were: not using any contraception at all $(193,59.9 \%)$, failure of contraceptive methods $(126,39.1 \%)$ and malformed fetuses $(3,1 \%)$. Although at the time of unintended conception cycles 82 (65\%) women had been using condoms, 24 (19\%) women had forgotten to use a condom and $58(46 \%)$ women had condom accidents. Furthermore, 16 (12.7\%) women missed pills for several days in a cycle, seven $(5.5 \%)$ women reported failed rhythm method and four $(3.3 \%)$ withdrawal failure. In total, $110(87.3 \%)$ women had been aware of the risk of pregnancy immediately after intercourse (recognisable contraceptive failure) when EC could have been used (Table 3 ).

\section{Discussion}

The widespread use of EC depends upon women's knowledge about it, their willingness to use it and its availability. The present survey revealed that only $5.9 \%$ (95\% CI 4.0-7.8) of the respondents knew about EC, while almost all $(99.7 \%)$ were willing to use it. This reflects the

Table 2 Knowledge and practice of contraceptive methods among the respondents $(\mathrm{n}=626)$

\begin{tabular}{lrr}
\hline Parameter & $n$ & $\%$ \\
\hline Knowledge of method & & \\
Condom & 620 & 99.0 \\
Intrauterine device & 622 & 99.4 \\
Pills & 624 & 99.7 \\
Injection/implant & 441 & 70.4 \\
Rhythm & 324 & 51.8 \\
Emergency contraception & 37 & 5.9 \\
Sterilisation (male/female) & 625 & 99.8 \\
Contraceptives ever used & & \\
Condom & 354 & 56.5 \\
Intrauterine device & 328 & 52.4 \\
Pills & 107 & 17.1 \\
Injection/implant & 6 & 1.0 \\
Rhythm & 51 & 8.1 \\
Emergency contraception & 0 & 0.0 \\
\hline
\end{tabular}




\section{ARTICLE}

Table 3 Induced abortion due to contraceptive method failure among the respondents $(\mathrm{n}=126)$

\begin{tabular}{lrr}
\hline Parameter & $n$ & $\%$ \\
\hline Recognisable contraceptive failure & 16 & 12.7 \\
$\quad$ Forgotten pill & 24 & 19.1 \\
Forgot to use condom & 58 & 46.0 \\
Condom rupture/leakage/slippage & 1 & 0.8 \\
$\quad$ Forgot to use Today® vaginal sponge & 7 & 5.5 \\
Rhythm failure & 4 & 3.2 \\
$\quad$ Withdrawal failure & & \\
Non-recognisable contraceptive failure & 4 & 3.2 \\
$\quad$ Failure of Today vaginal sponge & 12 & 9.5 \\
$\quad$ Intrauterine device & & \\
\hline
\end{tabular}

great need for creating awareness and imparting knowledge about the correct use of EC among Indian women. In contrast, over the last decade there has been a dramatic increase in knowledge about EC in developed countries, with over $70 \%$ of women having a good knowledge of EC with even higher awareness levels. ${ }^{12,13}$ However, the level of usage does not match the level of awareness. ${ }^{12,13}$ This suggests an urgent need for the easier availability of EC, which still remains a major challenge globally.

EC is rarely prescribed in India. ${ }^{14}$ Only $30-40 \%$ of general practitioners and $10 \%$ of paramedical staff are aware of it. ${ }^{15}$ Detailed knowledge about EC among practising gynaecologists is also limited. ${ }^{14}$ Two recently conducted national surveys did not include any questions about EC, 1,16 suggesting a lack of recognition of its potential use even by policymakers. Combined oral contraceptive pills, levonorgestrel-only contraceptive pills and copper-T IUDs are available in India. However, there is no dedicated product of combined oral contraceptive pills specially packaged, labelled and marketed as EC. Thus, dispensing four high-dose pills or eight low-dose pills creates confusion among both providers and users. ${ }^{17}$ Copper-T IUDs available in the national family planning programme have very low (1.6-1.9\%) acceptance among Indian women.1,16 Levonorgestrel-only pills were launched on the Indian market for the first time in early 2002. As of 2004, three preparations are marketed at a cost of 40-50 rupees (US\$ 1) per dose, which many Indian women find difficult to afford. Furthermore, as levonorgestrel-only pills are prescription-only drugs, a visit to a clinic or doctor is necessary to obtain them. These factors restrict their use. Considering the current Indian scenario, the consortium on national consensus for EC recommends awareness campaigns to educate the providers and users at all levels, training of health care providers, and the supply of levonorgestrel-only contraceptives through the established family planning network. ${ }^{15}$ Very recently, attempts have been initiated to supply levonorgestrel-only contraceptives free of cost through the national family planning programme.

Inclusion of $\mathrm{EC}$ in the family planning programme could have a substantial impact on reducing the rate of induced abortion. The present survey revealed that 126 $(39.1 \%)$ induced abortions were due to failure of contraceptive methods, which is roughly in line with the results of a recent government report. ${ }^{2}$ Based on our findings, and using a $75 \%$ efficacy rate for EC, ${ }^{5-8}$ it is estimated that the correct use of EC could have prevented nearly $65.5 \%$ (95\% CI 57.0-74.0) of induced abortions due to contraceptive method failure and $25.6 \%(95 \%$ CI 20.7-30.5) of all induced abortions.

Condoms, the commonest ever-used temporary method of contraception in this study, were used by $56 \%$ of respondents. Condom accidents have contributed to the majority of unwanted pregnancies in the current survey and in earlier reports. ${ }^{12,13}$ Therefore, educating clients regarding $\mathrm{EC}$ at the time of condom distribution could favourably affect the need for induced abortions. Furthermore, providing backup pregnancy protection by the use of EC might encourage the wider use of barrier contraceptive methods (currently shunned by women as having lower efficacy ${ }^{17}$ ), thus reducing sexually transmitted diseases including HIV. ${ }^{7}$ Although public knowledge about the availability and use of EC is limited, ${ }^{14,18}$ attempts have been made recently to develop methods to popularise EC among providers, policymakers and clients in India. ${ }^{15}$

The present survey has also shown that the majority $(59.9 \%)$ of induced abortions were due to failure to use any contraceptive method. This suggests that more efforts are required to generate awareness about the health hazards of induced abortion, which can be avoided by the use of effective contraception

Statements on funding and competing interests

Funding. None identified.

Competing interests. None identified.

References

1 National Family Health Survey (NFHS-2), International Institute for Population Sciences (IIPS) and ORC Macro. National Family Health Survey (NFHS-2), India, 1998-99. Mumbai, India: IIPS, 2001.

2 Ministry of Health and Family Welfare. Family Welfare Programme in India. Year Book 1997-98. New Delhi, India: Ministry of Health and Family Welfare, Government of India, 1998.

3 Khan ME, Barge S, George P. Abortion in India: an overview. Social Change 1996; 26: 208-225.

4 Das NP, Desai G, Patel R. Incidence of induced abortion in India: a study of socio-cultural aspects from NFHS data. Demography India 2000; 29: 149-164

5 Yuzpe AA, Percival-Smith R, Rademaker AW. A multi-centre clinical investigation employing ethinylestradiol combined with dl-norgestrel as a postcoital contraceptive agent. Fertil Steril 1982; 37: 508-513.

6 Trussell J, Rodriguez G, Ellertson C. New estimates of the effectiveness of the Yuzpe regimen of emergency contraception. Contraception 1998; 57: 363-369.

7 Cates W, Raymond EG. Emergency contraception - parsimony and prevention in the medicine cabinet. Am J Public Health 1997; 87: 909-910.

8 Task Force on Postovulatory Methods of Fertility Regulation. Randomised controlled trial of levonorgestrel versus the Yuzpe regimen of combined oral contraceptives for emergency contraception. Lancet 1998; 352: 428-433.

9 Grimes DA, Raymond EG. Emergency contraception. Ann Intern Med 2002; 137: 180-189.

10 Jackson R, Schwarz EB, Freedman L, Darney P. Knowledge and willingness to use emergency contraception among low-income postpartum women. Contraception 2000; 61: 351-357.

11 Kumari C. Contraceptive practices of women living in rural areas of Bihar. Br J Fam Plann 1998; 24: 75-77.

12 Gordon AF, Owen P. Emergency contraception: change in knowledge of women attending for termination of pregnancy from 1984 to 1996. Br J Fam Plann 1999; 24: 121-122.

13 Aneblom G, Larsson M, Odlind V, Taydén T. Knowledge, use and attitudes towards emergency contraceptive pills among Swedish women presenting for induced abortion. Br J Obstet Gynaecol 2002; 109: $155-160$.

14 Purwar M, Ughade S. Emergency contraception: what do healthcare providers know and think about it? Int J Gynecol Obstet India 2001; 4: $52-57$.

15 Consortium on National Consensus for Emergency Contraception. Report and Recommendations. WHO-CCR in Human Reproduction, All India Institute of Medical Sciences, New Delhi, India, 2001.

16 Reproductive and Child Health Project Rapid Household Survey (Phase I \& II) 1998-1999. Mumbai, India: International Institute for Population Sciences, 2001. http://unpan1.un.org/intradoc/groups/ public/documents/APCITY/UNPAN009850.pdf.

17 Chaudhuri SK. Practice of Fertility Control: A Comprehensive Manual (6th edn). New Delhi, India: Elsevier, 2004.

18 Sarkar NN. Emergency contraception. Int J Clin Pract 1999; 53: 199-204. 